\title{
Isolation and purification of all-trans diadinoxanthin and all-trans diatoxanthin from diatom Phaeodactylum tricornutum
}

\author{
Paulina Kuczynska $^{1}$ (D) Malgorzata Jemiola-Rzeminska ${ }^{1,2}$
}

Received: 20 July 2016 /Revised and accepted: 8 September 2016/Published online: 27 September 2016

(C) The Author(s) 2016. This article is published with open access at Springerlink.com

\begin{abstract}
Two diatom-specific carotenoids are engaged in the diadinoxanthin cycle, an important mechanism which protects these organisms against photoinhibition caused by absorption of excessive light energy. A high-performance and economical procedure of isolation and purification of diadinoxanthin and diatoxanthin from the marine diatom Phaeodactylum tricornutum using a four-step procedure has been developed. It is based on the use of commonly available materials and does not require advanced technology. Extraction of pigments, saponification, separation by partition and then open column chromatography, which comprise the complete experimental procedure, can be performed within 2 days. This method allows HPLC grade diadinoxanthin and diatoxanthin of a purity of $99 \%$ or more to be obtained, and the efficiency was estimated to be $63 \%$ for diadinoxanthin and $73 \%$ for diatoxanthin. Carefully selected diatom culture conditions as well as analytical ones ensure highly reproducible performance. A protocol can be used to isolate and purify the diadinoxanthin cycle pigments both on analytical and preparative scale.
\end{abstract}

Keywords Carotenoids · Chromatography $\cdot$ Diadinoxanthin · Diatoms $\cdot$ Diatoxanthin $\cdot$ Phaeodactylum tricornutum

Electronic supplementary material The online version of this article (doi:10.1007/s10811-016-0961-x) contains supplementary material, which is available to authorized users.

Paulina Kuczynska

kuczynska.paul@gmail.com

1 Department of Plant Physiology and Biochemistry, Faculty of Biochemistry, Biophysics and Biotechnology, Jagiellonian University, Gronostajowa 7, 30-387 Krakow, Poland

2 Malopolska Centre of Biotechnology, Gronostajowa 7A, 30-387, Krakow, Poland

\section{Introduction}

Carotenoids are the most widespread group of naturally occurring pigments composed of more than 700 structurally different compounds (Britton et al. 2004). They typically consist of $\mathrm{C}_{40}$ hydrocarbon backbone and are divided into two classes, carotenes - polyunsaturated hydrocarbons and xanthophyllstheir oxygenated derivatives. With conjugated double-bond system, carotenoids can absorb light in the visible range of the spectrum. This also causes the compounds to be deeply coloured; most of the carotenes are reddish and most of the xanthophylls are yellow-orange.

In photosynthetic organisms, carotenoids have two wellrecognized functions: one, as accessory light-harvesting pigments and, the other, as quenchers of singlet oxygen and chlorophyll triplet states to provide protection against photooxidative damage (Vílchez et al. 2011). Lycopene and $\beta, \beta$-carotene $(\beta \beta$-Car) are found in light-harvesting complexes (LHC) in plants and green algae (Koepke et al. 1996; Scheer 2003), while fucoxanthin (Fuco) is abundantly present in fucoxanthin-chlorophyll protein (FCP) complexes in diatoms (for review see Kuczynska et al. (2015)). The photoprotective role of carotenoids is based on their ability to quench excited molecules and scavenge free radicals to prevent the damage of photosynthetic apparatus caused by excess light energy. Some xanthophylls are capable of cyclic conversions through deepoxidation and epoxidation, referred to as the xanthophyll cycle. Violaxanthin (Viola), antheraxanthin (Anth) and zeaxanthin (Zea) are engaged in the most common violaxanthin cycle (VAZ cycle) which occurs in plants, mosses, lichens and algae (Yamamoto et al. 1962). In the primitive green alga Mantoniella squamata, the specific type of VAZ cycle has been described by Goss et al. (1998) and Gilmore and Yamamoto (2001), with Anth as the main product of deepoxidation instead of Zea. On the other hand, diatoms 
display the diadinoxanthin cycle (DD cycle) in which interconversion between epoxidised diadinoxanthin (Diadino) and epoxy-free diatoxanthin (Diato) occurs. However, the VAZ cycle can be also observed under specific conditions (Lohr \& Wilhelm 1999). Finally, in other organisms, the lutein epoxide cycle engaging lutein and lutein epoxide (Rabinowitch et al. 1975), as well as the siphonaxanthin cycle with lutein and siphonaxanthin (Raniello et al. 2006), were identified.

Carotenoids are natural bioactive compounds. Due to their beneficial activities such as antioxidant, anticancer, anti-inflammatory, anti-obesity and neuroprotective effects, they are of great importance for the food, cosmetic and pharmaceutical industries (Pangestuti \& Kim 2011). Carotenoid production both by extraction from plants and subsequent purification or through chemical synthesis is limited (for reviews see Coulson 1980 and Dufossé et al. 2005)). In this respect, the fact that carotenoids are widely distributed in microorganisms including bacteria, yeast, fungus and algae offers a promising alternative for carotenoids production, reviewed recently in (Mata-Gómez et al. 2014). Furthermore, since bioreactors allow successful cultivation of different species of marine microorganisms, including diatoms, the latter are considered a good source of natural pigments. Accordingly, the most abundant pigment in diatoms, fucoxanthin, is available at present as a pure extract with important bioactivities (Mikami \& Hosokawa 2013; Xia et al. 2013). Last but not least, it is worth mentioning that although a variety of metabolic engineering tools are available to manipulate the biosynthetic pathways, the production of some carotenoids is unachievable. This is due to the fact that our knowledge about the genes-encoding carotenoid biosynthetic enzymes in diatoms is still limited (Dambek et al. 2012).

In this paper, a method of extraction and purification of diatoxanthin and diadinoxanthin from Phaeodactylum tricornutum has been described. This unicellular alga is a cosmopolitan marine pennate diatom. Since both Diadino and Diato occur only in few algal groups including diatoms, these pigments might be considered as diatom-specific carotenoids. A four-step procedure including total pigment extraction, saponification, separation of carotenoids and open column chromatography enables to obtain all-trans isomers of Diadino and Diato of a purity of $99 \%$ or more. It is worth to refer this method to the isolation of fucoxanthin and peridinin described in (Haugan et al. 1995).

\section{Materials and methods}

\section{Reagents and chemicals}

The organic solvents (ethyl acetate, methanol, acetonitrile, acetone, hexane isomers mix, diethyl ether, water) were of HPLC grade and purchased from Rathburn Chemicals Ltd.
(Scotland) or Chromasolv (USA). The ammonium acetate p.a. was supplied by Avantor Performance Materials (Poland) and dissolved in HPLC grade water. For saponification and pigment partitioning, potassium hydroxide p.a. obtained from Avantor Performance Materials was used as well as rectified $95 \%$ ethanol and extraction petroleum purchased from Polmos (Poland) and Avantor Performance Materials, respectively. Silica gel (Silica gel 60, pore size 0.040 $0.063 \mathrm{~mm}$ (230-400 mesh ASTM)) purchased from Merck (Germany) were alkalised by hydrogen carbonate p.a. and washed by deionised water.

\section{HPLC analysis}

Pigment fractions collected in each step of the procedure were dried under a stream of nitrogen, dissolved in extraction medium (methanol, $0.2 \mathrm{M}$ ammonium acetate, ethyl acetate $(81: 9: 10, v / v))$ and analysed on a Nucleosil column (ET 250/ 8/4, 300-5, C18; Macherey \& Nagel, Germany) by HPLC, applying a gradient according to Kraay et al. (1992). The elution was performed using solvent A (methanol, $0.5 \mathrm{M}$ aqueous ammonium acetate, 85:15 v/v), solvent B (acetonitrile to water, 90:10 v/v) and solvent $\mathrm{C}$ (ethyl acetate) in a linear gradient (minutes $/ \%$ solvent $\mathrm{A} / \%$ solvent $\mathrm{B} / \%$ solvent $\mathrm{C}$ ): 0/60/40/0, 2/0/100/0, 7/0/80/20, 17/0/50/50, 21/0/30/70, $28.5 / 0 / 30 / 70,29.5 / 0 / 100 / 0,30.5 / 60 / 40 / 0$, at a flow rate of

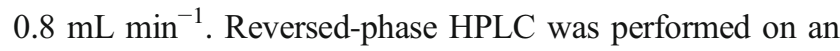
Agilent 1200 Series HPLC system equipped with a photodiode array detector and controlled by Agilent ChemStation software. Pigments were identified by comparing the on-line spectra with data from the literature and quantified using calibration curves calculated with standards, according to Lohr (2000). Absorption spectra were monitored at four wavelengths: 430, 440, 480 and $665 \mathrm{~nm}$. The content $\left(n / V_{\mathrm{ex}}\right)$ of each pigment was calculated by the following formula: ( $(A /$ $\left.\left.A_{\mathrm{c}} / \mathrm{MW} * 1000\right) * V_{\mathrm{ex}}\right) / V_{\text {inj }}$ where $A$ is the peak area, $A_{c}$ is the peak area $\mathrm{ug}^{-1}$ pigment, MW is the molar weight, $V_{\mathrm{ex}}$ is the extract volume, $V_{\mathrm{inj}}$ is the injection volume and $n$ is the number of moles.

\section{Culture conditions}

Phaeodactylum tricornutum Bohlin strain CCAP 1055/1 was obtained from the Culture Collection of Algae and Protozoa, UK. Cultures were grown in f/2-Si medium (Guillard 1975) made with artificial seawater supplemented with inorganic nutrients and vitamin mixture at $15^{\circ} \mathrm{C}$, under white light (absorption spectrum in A.1 in Supplementary Material A) of $100 \mu \mathrm{mol}$ photons $\mathrm{m}^{-2} \mathrm{~s}^{-1}$ in a $16 / 8 \mathrm{~h}$ day/night photoperiod. Cells were inoculated every 3 or 4 days to maintain exponential phase of growth and reduce the number of dead cells. To provide optimal oxygen conditions, the volume of culture was lower than half of the flask volume and the number of cells 
was between $1 \times 10^{6}$ to $3 \times 10^{6}$ cells $\mathrm{mL}^{-1}$ which were counted microscopically in a Malassez chamber (Brand, Germany). The experiments were performed in flasks containing $1 \mathrm{~L}$ of diatom culture with initial density of $1 \times 10^{6}$ cells $\mathrm{mL}^{-1}$, which were grown for 3 or 4 days to obtain density of approximately $3 \times 10^{6}$ cells $\mathrm{mL}^{-1}$. A day before sample collection, the cells were inoculated into fresh medium to obtain $2 \times 10^{6}$ cells $\mathrm{mL}^{-1}$. To examine the level of Diadino (results shown in Fig. 1), samples were collected for 5 days in light period, after $1 \mathrm{~h}$ of incubation in darkness. One-day-old culture was chosen as an appropriate for Diadino purification. To examine the level of Diato (results are shown in Fig. 2), cultures were illuminated with $1250 \mu \mathrm{mol}$ photons $\mathrm{m}^{-2} \mathrm{~s}^{-1}$ white light for $5 \mathrm{~h}$ and samples were collected in every hour. Twohour illumination was applied to Diato purification. In each case, the cells were harvested through centrifugation for $5 \mathrm{~min}$ at $8000 \times g$ at $4{ }^{\circ} \mathrm{C}$. Pellet was frozen in liquid nitrogen and stored at $-20^{\circ} \mathrm{C}$ for no more than 1 week.

\section{Pigment extraction}

Pigments were extracted from frozen cells through addition of extraction medium composed of methanol, $0.2 \mathrm{M}$ ammonium acetate and ethyl acetate (81:9:10, $v / v$ ) based on Snoeijs et al. (2012), in a ratio of $10 \mathrm{~mL}$ per $2 \times 10^{9}$ cells. The mixture was vortexed thoroughly and centrifuged for $4 \mathrm{~min}$ at $14000 \times \mathrm{g}$ at $4{ }^{\circ} \mathrm{C}$. Supernatants were collected and evaporated in an inert gas atmosphere to remove volatile compounds. To minimize the risk of destruction or undesired reactions, all manipulations during isolation and analysis should be carried out with some general precautions described in details in Rodriguez-Amaya (2001) and Schiedt \& Liaaen-Jensen (1995) to avoid peroxidecontaining ethers, strong light, room temperature and oxygen in air.

\section{Saponification and pigment partitioning}

To semi-dried extract from $2 \times 10^{9}$ cells ethanol was added up to $35 \mathrm{~mL}$, followed by subsequent addition of aqueous potassium hydroxide $(60 \% w / v, 3.5 \mathrm{~mL})$ (Goodwin 1955). Solution was mixed gently for 15-20 h at $4{ }^{\circ} \mathrm{C}$. To separate chlorophylls from carotenoids, a volume of $40 \mathrm{~mL}$ hexane: diethyl ether $(1: 1 \mathrm{v} / \mathrm{v}), 10 \mathrm{~mL}$ extraction petroleum and $20 \mathrm{~mL}$ water were subsequently added, mixed gently and left to phase separate. Upper phase containing carotenoids was collected while lower phase was used to repeat the separation by using a volume of $10 \mathrm{~mL}$ hexane: diethyl ether $(1: 1 \mathrm{v} / \mathrm{v}), 2.5 \mathrm{~mL}$ extraction petroleum and $5 \mathrm{~mL}$ water. Then carotenoids fractions were combined and washed three times with $50 \mathrm{~mL}$ of water. To avoid formation of emulsions, gentle swirling was applied and final solution was transparent. It was evaporated in an inert gas atmosphere and stored at $-20^{\circ} \mathrm{C}$ for no more than 1 month.

\section{Open column chromatography}

Silica gel was modified according to Nagy et al. (2009), namely by stirring with saturated aqueous sodium hydrogen carbonate solution for $2 \mathrm{~h}$, filtration and washing with deionised water, then with acetone followed by drying under the hood. Modified gel was named silica-9 because of the $\mathrm{pH}$ of its aqueous suspension. An amount of $20 \mathrm{~g}$ of silica-9 was suspended in hexane: acetone $(90: 10 \mathrm{v} / \mathrm{v})$, put in a $15-\mathrm{mm}$ diameter glass column and applied to the chromatography of carotenoid fraction obtained from $2 \times 10^{9}$ cells. Upon dissolving in approximately $3 \mathrm{~mL}$ hexane: acetone ratio $(90: 10 \mathrm{v} / \mathrm{v})$, the sample was applied on the column and elution with hexane to acetone ratio $(90: 10 v / v)$ was carried out until the first fraction was collected. Then, the eluent was changed to hexane: acetone $(80: 20 v / v)$ and the second small fraction was observed and collected. The continued elution resulted in separation of further fraction, which was Diato. Once Diato was collected, the change of eluent to hexane: acetone $(70: 30 \mathrm{v} / \mathrm{v})$ resulted in separation and collection of Diadino fraction. The last coloured band remaining on the top of the column was removed by acetone. After conditioning with hexane: acetone $(90: 10 v / v)$, the gel was reused. Collected samples of Diadino and Diato were evaporated in an inert gas atmosphere and stored at $-80{ }^{\circ} \mathrm{C}$.

\section{Statistical analysis}

Each step of Diadino or Diato purification was performed in four replications which are represented by four individual diatom cultures constituting material to extraction of total pigments and subsequent purification steps. The level of pigments was expressed both as the percentage value and the absolute amount. The data shown in figures and tables are means of four replicates (three to seven replicates in Figs. 1 and 2). Statistical analysis included the determination of confidence intervals $(\mathrm{CI})$ for a significance level $(P)$ set to 0.05 . Parameters such as standard deviation (SD), standard error (SE), significance level (P), lower limit of the confidence interval $\left(\mathrm{CI}_{\min }\right)$, upper limit of the confidence interval $\left(\mathrm{CI}_{\max }\right)$ are given in Supplementary materials (Table A.1).

\section{Results and discussion}

\section{Culture conditions of diatoms}

Regardless of the type of the xanthophyll cycle, the enzymatic removal of epoxy groups from xanthophylls occurs as a consequence of strong light treatment. On the other hand, light is 
necessary to ensure the elevated content of epoxidised xanthophylls in cells. Thus, special attention should be paid to the light conditions. Understandably, for these studies, diatoms were cultivated under high light, and depending on whether Diadino or Diato was to be collected, the cells were harvested in dark or light phase, respectively. Several culture conditions including illumination with white light of two intensities (1250 and $700 \mu \mathrm{mol}$ photons $\mathrm{m}^{-2} \mathrm{~s}^{-1}$ ), for hours or days, in dark or light periods were tested. These preliminary studies have shown that while high levels of Diadino (up to $19 \%$ of total pigments) and Diato (up to $17 \%$ of total pigments) were obtained under a strong light, formation of cis-Diadino and cis-Diato and also an increase in Viola, Anth and Zea levels (A.3 in Supplementary Material) were observed, which made purification procedure even more difficult. Finally, white light of the intensity of $100 \mu \mathrm{mol}$ photons $\mathrm{m}^{-2} \mathrm{~s}^{-1}$ in a $16 / 8 \mathrm{~h}$ day/night photoperiod was chosen as the most appropriate. Such medium light allowed a higher Diadino level (even $10 \%$ (Fig. 1)) to be obtained compared to $7 \%$ found in the cells growing under low light $\left(30 \mu \mathrm{mol}\right.$ photons $\left.\mathrm{m}^{-2} \mathrm{~s}^{-1}\right)$ (A.3 in Supplementary Material). Concurrently, neither cis isomers nor the VAZ cycle pigment formation occurred (A.3 in Supplementary Material). Pigment content was measured during 5 days after $1 \mathrm{~h}$ of storage in darkness in the exponential phase of growth. Figure 1 shows the percentage values of each pigment found in sample extracts, including chlorophyll $a(\mathrm{Chl} a)$, chlorophyll $c_{1}$ and $c_{2}$ $(\mathrm{Chl} c$ ), chlorophillide (Chlide), fucoxanthin (Fuco), $\beta, \beta-$

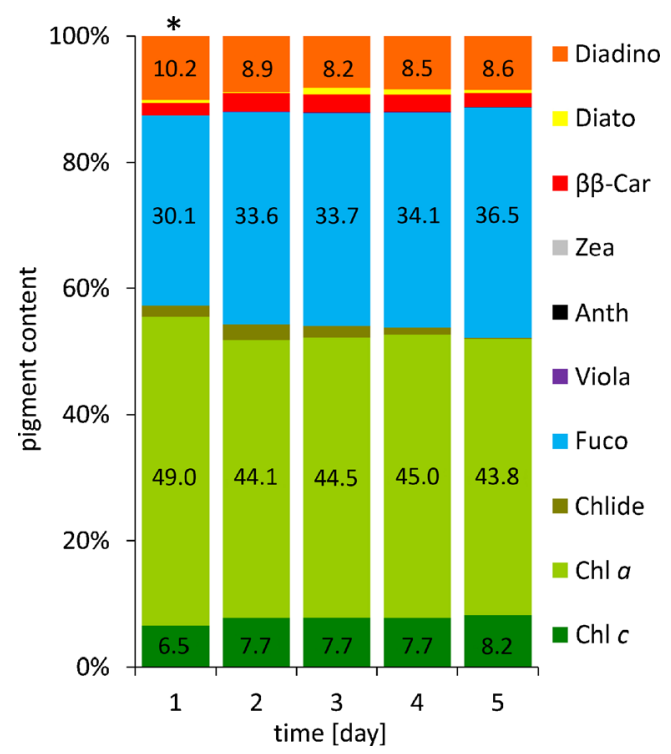

Fig. 1 Dependence of pigment content on number of days of diatom culture. Phaeodactylum tricornutum was cultivated at $15{ }^{\circ} \mathrm{C}$, under white fluorescent light $\left(100 \mu \mathrm{mol}\right.$ photons $\left.\mathrm{m}^{-2} \mathrm{~s}^{-1}\right)$ in a $16 / 8 \mathrm{~h}$ day/ night photoperiod. Samples were collected after $1 \mathrm{~h}$ of darkness. Pigment content was determined by HPLC and expressed as a percentage value. The data are means of three replicates; a sample marked with an asterisk is mean of seven replicates. Statistical data are given in Table A.1 in Supplementary Material carotene ( $\beta \beta$-Car), diadinoxanthin (Diadino), diatoxanthin (Diato), antheraxanthin (Anth), violaxanthin (Viola) and zeaxanthin (Zea). It is noteworthy that on the first day after inoculation, Diadino level was the highest and this time was chosen as an appropriate to collect sample. Aforementioned conditions have also been applied for the culture of $P$. tricornutum to obtain Diato with one exception, namely before collection cells were illuminated with white light of the intensity of $1250 \mu$ mol photons $\mathrm{m}^{-2} \mathrm{~s}^{-1}$ for no more than $2 \mathrm{~h}$. This exposure time resulted in that Diato achieved the level of $6 \%$ of the total pigment content. Although, continued illumination caused an increase in Diato content but evoked formation of Zea (Fig. 2). Here, it is worth pointing out that even small amounts of Viola, Anth and Zea, when present in pigment extract, are irremovable throughout the whole procedure, and final fractions of Diadino and Diato are contaminated with almost the same amounts of the VAZ cycle pigments as those found in the sample undergoing purification.

\section{Pigment extraction}

The efficiency of pigment extraction were found to be dependent on two factors, namely the composition of extraction medium and the proportion between this solvent volume and the number of cells. Several kinds of extraction media have been tested by Snoeijs et al. (2012). Based on their studies, it was decided to use an extraction medium composed of

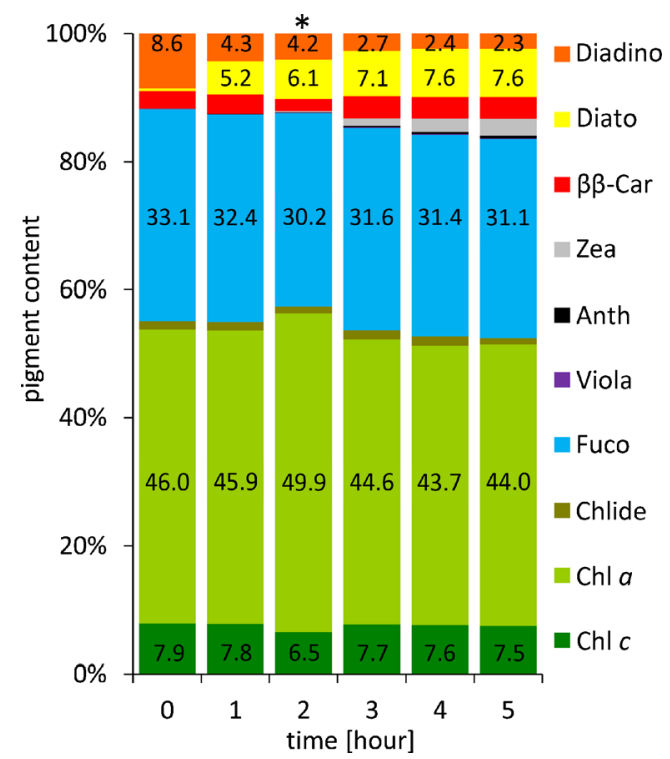

Fig. 2 Pigment content in one-day diatom culture illuminated with $1250 \mu \mathrm{mol}$ photons $\mathrm{m}^{-2} \mathrm{~s}^{-1}$ for $5 \mathrm{~h}$. Phaeodactylum tricornutum was cultivated at $15{ }^{\circ} \mathrm{C}$, under white fluorescent light (100 $\mu$ mol photons $\left.\mathrm{m}^{-2} \mathrm{~s}^{-1}\right)$ in a $16 / 8 \mathrm{~h}$ day/night photoperiod. Samples were collected every hour. Pigment content was determined by HPLC and expressed as a percentage value. The data are means of three replicates; a sample marked with an asterisk is mean of seven replicates. Statistical data are given in Table A.1 in Supplementary Material 
Fig. 3 Pigment content of carotenoid fractions obtained for three consecutive partitioning subsequent to saponification in the diadinoxanthin and diatoxanthin purification procedure. Pigment content was determined by HPLC and expressed as a percentage value and as an absolute amount obtained from $2 \times 10^{9}$ diatom cells. The data are means of four replicates. Statistical data are given in Table A.1 in Supplementary Material

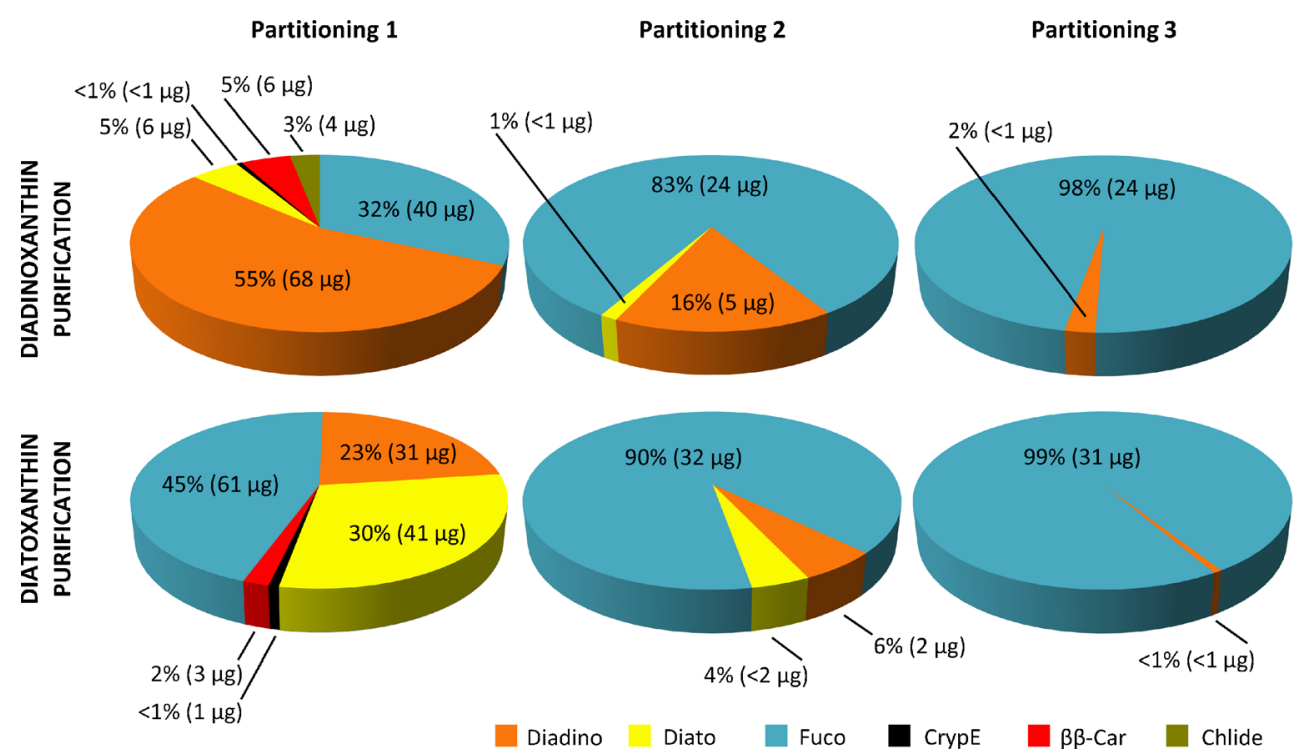

methanol, ammonium acetate and ethyl acetate due to its high efficiency in Diadino extraction accompanied by low capability of Chl $a$ and $\beta \beta$-Car removal. Moreover, the presence of ammonium ions allows reduction in or even inhibition of isomerization of all-trans to cis forms of carotenoids. The most appropriate proportion between volume of extraction medium and the number of cells yielding the highest extraction recovery for Diadino and Diato was found to be of $10 \mathrm{~mL}$ per $2 \times 10^{9}$ of diatom cells. To check the content of non-extracted pigments re-extraction was performed, which confirmed high efficiency of the first extraction (A.4 in Supplementary Material). Last but not least, it has been shown that gentle vortexing of suspended cells is sufficient and additional homogenization with glass beads has no impact on extraction efficiency (A.5 Supplementary Material).

\section{Saponification and pigment partitioning}

Alkaline saponification of pigment extract and liquidliquid partitioning by polar and non-polar solvents allow the removal chlorophylls and lipids, which upon saponification are easily separated from hydrophobic carotenoids. Since in $P$. tricornutum chlorophylls make up more than $50 \%$ of pigments (Fig. 1), their removal substantially contributes to the enrichment of Diadino and Diato. Taking
Table 1 The consecutive steps of separation by open column chromatography using silica-9 as a stationary phase. Approximate volumes of eluents and runtime are given for the following conditions: (i) $20 \mathrm{~g}$ of dry silica-9 suspended in hexane: acetone $(90: 10 v / v)$ was applied to the column; (ii) glass chromatography column with filter disc, $15 \mathrm{~mm}$; (iii) evaporated carotenoid fraction after saponification of pigment extract obtained from $2 \times 10^{9}$ cells was dissolved in hexane: acetone $(90: 10 v / v)$ and applied to the column; (iv) chromatography was carried out at room temperature

\begin{tabular}{|c|c|c|}
\hline Eluent & Description & Product \\
\hline $\begin{array}{l}\text { Hexane: acetone } \\
\qquad(90: 10 v / v)\end{array}$ & $\begin{array}{l}\text { Clearly separated band migrates down through } \\
\text { the column for approximately } 25 \text { min and approximately } \\
40 \mathrm{~mL} \text { of eluent is used. Three to four millilitres of } \\
\text { this fraction is collected. }\end{array}$ & $\begin{array}{c}\beta, \beta \text {-Carotene and } \\
\text { its derivatives }\end{array}$ \\
\hline \multirow[t]{2}{*}{$\begin{array}{l}\text { Hexane: acetone } \\
\quad(80: 20 \mathrm{v} / \mathrm{v})\end{array}$} & $\begin{array}{l}\text { After the change of eluent, a hardly visible band (more } \\
\text { intensive in the case of Dtx purification) migrates for } \\
\text { about } 30 \mathrm{~min} \text { and approximately } 50 \mathrm{~mL} \text { of eluent is } \\
\text { used. A volume of } 6-8 \mathrm{~mL} \text { of this fraction is collected. }\end{array}$ & Cryptoxanthin-epoxide \\
\hline & $\begin{array}{l}\text { Third band is very intense and in half-length of column, } \\
\text { it splits into two bands, which become better separated } \\
\text { with time. From the second fraction, migration of the } \\
\text { third one takes about } 50 \text { min and approximately } 80 \mathrm{~mL} \\
\text { of eluent is used. A volume of } 14-20 \mathrm{~mL} \text { of this fraction } \\
\text { is collected; in the case of Dtx purification, their colour } \\
\text { is very intensive. }\end{array}$ & Diatoxanthin \\
\hline $\begin{array}{l}\text { Hexane: acetone } \\
\qquad(70: 30 v / v)\end{array}$ & $\begin{array}{l}\text { Clearly marked band migrates for about } 20 \text { min since Dtx } \\
\text { is collected and approximately } 40 \mathrm{~mL} \text { of eluent is used. } \\
\text { A volume of } 15-22 \mathrm{~mL} \text { of this fraction is collected. }\end{array}$ & Diadinoxanthin \\
\hline Acetone & $\begin{array}{l}\text { Acetone results in migration of all remaining fractions, } \\
\text { which are visible as four blurred bands collected together } \\
\text { in a volume of } 17-25 \mathrm{~mL} \text {. Their migration takes about } \\
30 \mathrm{~min} \text { and approximately } 60 \mathrm{~mL} \text { of eluent is used. }\end{array}$ & Fucoxanthin derivatives \\
\hline
\end{tabular}


into account that some carotenoids including epoxy-carotenoids, i.e. Fuco, are unstable in alkali (Khachik 1986; Maoka 2016), saponification, in general, is not recommended. It is believed that the extent of degradation depends on the conditions used, being greater with higher concentration of alkali and on hot saponification (Kimura
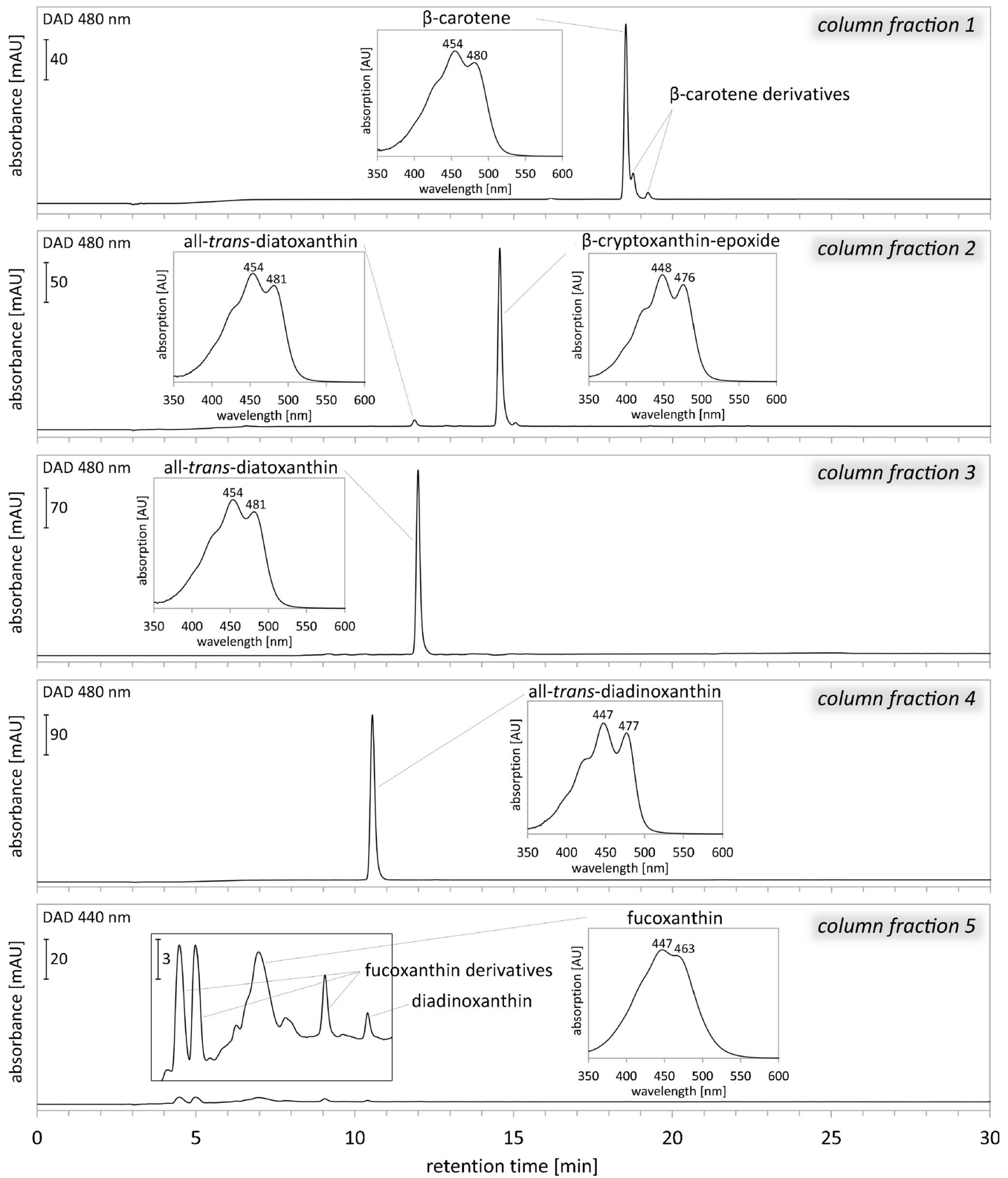

Fig. 4 Chromatograms obtained with the method by Kraay and co-workers (see "Materials and methods" section) and absorption spectra recorded during HPLC-DAD analysis for consecutive carotenoid fractions collected from open column chromatography 
Fig. 5 The amount of pigments in each fraction collected from the column which was obtained at the end of the purification process of pigments extracted from $2 \times 10^{9}$ cells. Pigment content was determined by HPLC and expressed as an absolute amount. The error bars represent standard deviation (SD). The data are means of four replicates. Statistical data are given in Table A.1 in Supplementary Material

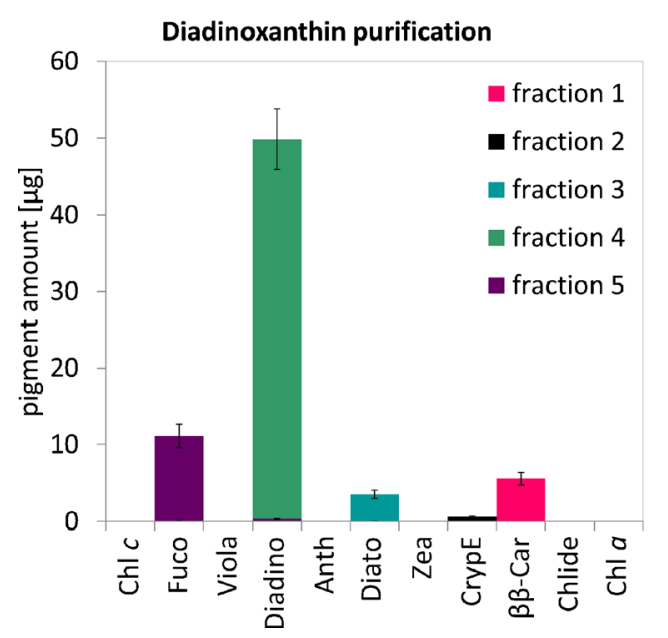

1990). Saponification described in this paper resulted in Chl $a$, Fuco and $\beta \beta$-Car degradation but had no impact on Diadino and Diato (see chromatograms of fractions eluted from column in Fig. 4). Then, partitioning carried out with the use of hexane: diethyl ether $(1: 1 v / v)$, extraction petroleum and water in proportion 4:1:2 $(v / v)$ gave great separation result. The use of hexane and diethyl ether was found not to be sufficient, and as a result, no partitioning was observed (A.6 in Supplementary Material). The effect of the addition of petroleum was only slight, and finally, combination of all four components could provide the excellent partitioning results with sharp phase boundaries (A.6 Supplementary Material). Three repetitions of partitioning were performed but single steps allowed to recover most of Diadino $(68 \mu \mathrm{g})$ or Diato $(41 \mu \mathrm{g})$ and left only 5 or $1.5 \mu \mathrm{g}$, respectively (Fig. 3). In the second and third partitioning, Fuco was the dominant pigment, $83 \%$ or even $99 \%$ (Fig. 3). The content of
Diadino or Diato in second partitioning was 16 or $4 \%$, respectively and therefore it seems reasonable to ignore these steps.

Combined carotenoid fractions obtained from partitioning subsequent to saponification are to be subjected to washing with distilled water to remove alkali. While agitation of the mixture is typically recommended, it was found to lead to the formation of an emulsion which was difficult to break and resulted in the loss of carotenoids to the aqueous phase. Instead, gentle swirling reached expectations and upon three repetitions of washing, a transparent solution was obtained (A.7 in Supplementary Material).

\section{Open column chromatography}

Open column chromatography is widely used as a method of choice to separate and purify photosynthetic pigments. However, calcium carbonate, alumina, magnesium oxide

\section{Efficiency [\%] Enrichment [\%]}

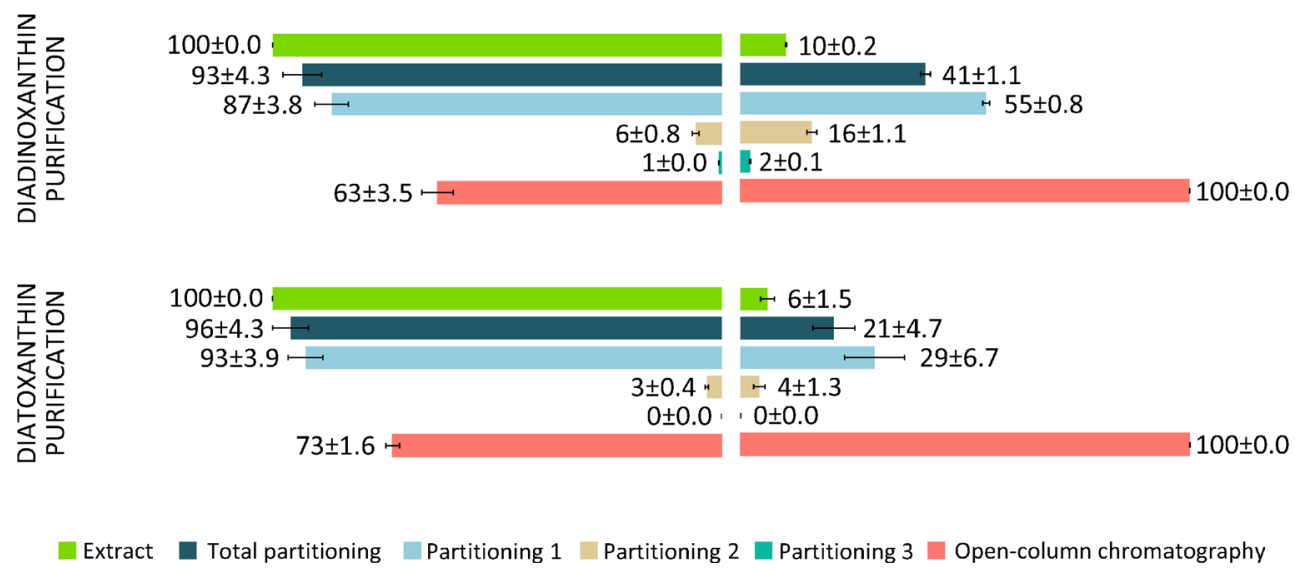

Fig. 6 Efficiency (left side) and enrichment (right side) of diadinoxanthin and diatoxanthin purification in each step of the procedure. Partitioning 1, 2 and 3 represent first, second and third carotenoid fractions; total partitioning represents total yield estimated for three combined carotenoid fractions subjected to separation by partition. Pigment content was determined by HPLC and expressed as a percentage. The error bars represent standard deviation (SD). The data are means of four replicates. Statistical data are given in Table A.1 in Supplementary Material 
etc., which are very efficient and do not cause decomposition of carotenoids, are characterized by very small capacity. The latter makes them practically unfavourable when considering preparative scale chromatography. On the other hand, silica gels of high capacities, due to their acidic character are not suitable for carotenoids (Bernhard 1995; Nagy et al. 2009). To overcome this problem, eluent is often enriched with triethylamine; however, the base is then difficult to remove as well as changes in the retention occur. Therefore, following the idea of Nagy et al. (2009), modified silica gel, which is chemically converted to a basic form and retains high capacity, was used. Application of silica-9 and gradient elution with hexane and acetone to separate Diato and Diadino from other carotenoids and also from each other was proved to be efficient. Moreover, it induced no transformation or decomposition of the DD cycle pigments. It should be noticed that the use of $n$-hexane instead of hexane mix of isomers in this chromatography completely stops migration from the second fraction. The steps of chromatographic separation are described in Table 1.

Each fraction collected from the open column chromatography was analysed by HPLC (Fig. 4). Chromatogram recorded for the first fraction consisted of three peaks identified as $\beta \beta$-Car and its derivatives (Fig. 5) in an amount of 5.5 to $6.5 \mu \mathrm{g}$ (Fig. 6). The second fraction included mainly CrypE ( $89 \%$ in Diadino or $91 \%$ in Diato purification) and low amount of Diato and Fuco derivatives (Figs. 5 and 6). The third fraction was all-trans Diato, with its amount in samples intended for Diadino purification of approximately $4 \mu \mathrm{g}$ and much higher $(32 \mu \mathrm{g})$ in the case of Diato purification (Figs. 5 and 6). The fourth fraction corresponded to all-trans Diadino in the amount of 23 or $50 \mu \mathrm{g}$ during Diato or Diadino purification, respectively (Figs. 5 and 6). The fifth fraction included traces of Fuco derivatives (11 to $34 \mu \mathrm{g}$ ) and Diadino (less than $0.3 \mu \mathrm{g}$ ) (Figs. 5 and 6). Elution of the fifth fraction is not necessary; however, after its removal, the silica gel might be reused. The purity of Diadino and Diato was estimated to be of $99 \%$ or more. The amounts of purified pigments obtained from $2 \times 10^{9}$ diatom cells were $2.44 \times 10^{-7}$ and $1.16 \times 10^{-7} \mathrm{~g}$ for Diadino and Diato, respectively.

\section{Efficiency of diatoxanthin and diadinoxanthin purification}

The efficiency of each step in the Diadino or Diato purification procedure was estimated based on the amount of collected pigments and it is shown in Fig. 6. While the pigment extract included $10 \%$ of Diadino and $6 \%$ of Diato, separation by partition resulted in the significant enrichment of Diadino (41\%) and Diato (21\%) and only slight loss of this pigment was noted. This yielded the efficiency of this step at the very high level of approximately $90 \%$ (Fig. 6). However, the first partitioning was the most efficient whereas the second and the third ones increased this value only of 6 and $3 \%$ for Diadino and Diato, respectively. Thus, taking into account the time and chemical cost, the repetitions might be skipped. The open column chromatography resulted in the most pronounced loss of pigment. Final efficiency of described purification procedure was estimated to be $63 \%$ for Diadino and $73 \%$ for Diato.

\section{Conclusions}

In this paper, a method of all-trans diatoxanthin and all-trans diadinoxanthin purification from marine diatom P. tricornutum has been described. The protocol consists of four steps including pigment extraction, saponification, separation by partition and open column chromatography. Conditions of diatom culture were optimized paying special attention to the light to produce high content of Ddx and Dtx and concurrently to avoid the formation of their cis isomers as well as the VAZ cycle pigments. Extraction medium consisted of methanol, ammonium acetate and ethyl acetate which ensured efficient extraction of Ddx and Dtx from diatom cells. By use of the four component mixture with hexane: diethyl ether $(1: 1 v / v)$, petroleum and water in proportion $4: 1: 2(v / v)$, an excellent separation of chlorophylls and carotenoids was achieved, which contributed to the significant enrichment of Ddx and Dtx. Finally, by open column chromatography with alkalised silica gel, Ddx and Dtx were collected of a purity of $99 \%$ or more. Final efficiency of our purification procedure was estimated to be $63 \%$ for Ddx and $73 \%$ for Dtx and enabled to get about $30-50 \mu \mathrm{g}$ of these xanthophylls from $1 \mathrm{~L}$ of diatom culture with density of $2 \times 10^{6}$ cells $\mathrm{mL}^{-1}$. This procedure is dedicated to both analytical and preparative scale. This is of special importance given that until now neither Ddx nor Dtx were commercially available in amounts greater than those used as HPLC standards.

Acknowledgments This work was supported by the Grant 2013/09/N/ NZ1/01031 from the National Science Center Poland. The Jagiellonian University is a partner of the Leading National Research Center (KNOW) supported by the Ministry of Science and Higher Education. HPLC analysis was carried out with the equipment purchased thanks to the financial support of the European Regional Development Fund in the framework of the Polish Innovation Economy Operational Program POIG.02.01.0012-167/08. A method of diadinoxanthin and diatoxanthin purification has been reported as patent applications P.412178 and P.412177 (Kuczynska \& Jemiola-Rzeminska 2015), and PCT/PL2016/000047 (Kuczynska \& Jemiola-Rzeminska 2016).

\section{Compliance with ethical standards}

Conflict of interest The authors declare that they have no conflict of interest. 
Open Access This article is distributed under the terms of the Creative Commons Attribution 4.0 International License (http:// creativecommons.org/licenses/by/4.0/), which permits unrestricted use, distribution, and reproduction in any medium, provided you give appropriate credit to the original author(s) and the source, provide a link to the Creative Commons license, and indicate if changes were made.

\section{References}

Bernhard K (1995) Chromatography: part II column chromatography. In: Britton G, Liaaen-Jensen S, Pfander H (eds) Carotenoids volume 1A: isolation and analysis. Birkhäuser Verlag, Basel, pp. 117-130

Britton G, Liaaen-Jensen S, Pfander H (eds) Mercandante AZ, Egeland ES (compilers) (2004) Carotenoids handbook. 1st ed. Birkhäuser Verlag, Basel.

Coulson J (1980) Miscellaneous naturally occurring coloring materials for foodstuff. In: Walford J (ed) Developments in food colour. Applied Science Publishers, London, pp. 189-218

Dambek M, Eilers U, Breitenbach J, Steiger S, Büchel C, Sandmann G (2012) Biosynthesis of fucoxanthin and diadinoxanthin and function of initial pathway genes in Phaeodactylum tricornutum. J Exp Bot 63:5607-5612

Dufossé L, Galaup P, Yaron A, Arad SM, Blanc P, Murthy KNC, Ravishankar GA (2005) Microorganisms and microalgae as sources of pigments for food use: a scientific oddity or an industrial reality? Trends Food Sci Technol 16:389-406

Gilmore AM, Yamamoto HY (2001) Time-resolution of the antheraxanthin and delta $\mathrm{pH}$-dependent chlorophyll a fluorescence components associated with photosystem II energy dissipation in Mantoniella squamata. Photochem Photobiol 74:291-302

Goodwin TW (1955) Carotenoids. In: Paech K, Tracey MV (eds) Modern Methods of Plant Analysis, vol 3. Springer, Berlin, pp. 272-311

Goss R, Böhme K, Wilhelm C (1998) The xanthophyll cycle of Mantoniella squamata converts violaxanthin into antheraxanthin but not to zeaxanthin: consequences for the mechanism of enhanced non-photochemical energy dissipation. Planta 205:613-621

Guillard RRL (1975). Culture of marine invertebrate animals. In: Smith WL, Chanley MH (eds), Culture of Phytoplankton for Feeding Marine Invertebrates. Springer US, pp 29-60

Haugan JA, Aakermann T, Liaaen-Jensen S (1995) Example 2: macroalgae and microalgae. In: Britton $\mathrm{G}$, Liaaen-Jensen $\mathrm{S}$, Pfander $\mathrm{H}$ (eds) Carotenoids volume 1A: isolation and analysis. Birkhäuser Verlag, Basel, pp. 215-226

Khachik F, Beecher GR, Whittaker NF (1986) Separation, identification, and quantification of the major carotenoid and chlorophyll constituents in extracts of several green vegetables by liquid chromatography. J Ag Food Chem 34:603-616

Kimura M, Rodriguez-Amaya DB, Godoy HT (1990) Assessment of the saponification step in the quantitative determination of carotenoids and provitamins A. Food Chem 35:187-195

Koepke J, Hu X, Muenke C, Schulten K, Michel H (1996) The crystal structure of the light-harvesting complex II (B800-850) from Rhodospirillum molischianum. Structure 4:581-597
Kraay GW, Zapata M, Veldhuis MJW (1992) Separation of chlorophylls $\mathrm{c}_{1} \mathrm{c}_{2}$, and $\mathrm{c}_{3}$ of marine phytoplankton by reversed-phase-C18-highperformance liquid chromatography. J Phycol 28:708-712

Kuczynska P, Jemiola-Rzeminska M, Strzalka K (2015) Photosynthetic pigments in diatoms. Mar Drugs 13:5847-5881

Lohr M (2000). Beziehungen zwischen den Xanthophyllzyklen und der Biosynthese von Lichtsammelxanthophyllen in Chlorophyll a/chaltigen Algen. Thesis, Johannes Gutenberg-Universität Mainz.

Lohr M, Wilhelm C (1999) Algae displaying the diadinoxanthin cycle also possess the violaxanthin cycle. Proc Nat Acad Sci U S A 96: 8784-8789

Maoka, T. (2016). Structural studies of carotenoids in plants, animals and food. In: Baranska M, Kaczor A (eds), Carotenoids: Nutrition, Analysis and Technology. John Wiley \& Sons, Ltd., pp 103-131

Mata-Gómez LC, Montañez JC, Méndez-Zavala A, Aguilar CN (2014) Biotechnological production of carotenoids by yeasts: an overview. Microb Cell Factories 13:12. doi:10.1186/1475-2859-13-12

Mikami K, Hosokawa M (2013) Biosynthetic pathway and health benefits of fucoxanthin, an algae-specific xanthophyll in brown seaweeds. Int J Molec Sci 14:13763-13781

Nagy V, Agócs A, Turcsi E, Deli J (2009) Isolation and purification of acid-labile carotenoid 5,6-epoxides on modified silica gels. Phytochem Anal 20:143-148

Pangestuti R, Kim SK (2011) Biological activities and health benefit effects of natural pigments derived from marine algae. J Funct Foods 3:255-266

Rabinowitch HD, Budowski P, Kedar N (1975) Carotenoids and epoxide cycles in mature-green tomatoes. Planta 122:91-97

Raniello R, Lorenti M, Brunet C, Buia MC (2006) Photoacclimation of the invasive alga Caulerpa racemosa var. cylindracea to depth and daylight patterns and a putative new role for siphonaxanthin. Mar Ecol 27:20-30

Rodriguez-Amaya DB (2001). A guide to carotenoid analysis in foods. ILSI Human Nutrition Institute.

Scheer H (2003) The pigments. In: Green B, Parson WW (eds) Lightharvesting antennas in photosynthesis. Springer, Dordrecht, pp. 29 81

Schiedt K, Liaaen-Jensen S (1995) Isolation and analysis. In: Britton G, Liaaen-Jensen S, Pfander H (eds) Carotenoids: isolation and analysis, vol 1A. Birkhäuser Verlag, Basel, pp. 81-108

Snoeijs P, Häubner N, Sylvander P, Nie X-P (2012) Measurement of antioxidant pigments and vitamins in phytoplankton, zooplankton, and fish. In: Abele D, Vazquez-Medina JP, Zenteno-Savin T (eds) Oxidative stress in aquatic ecosystems. Blackwell Publishing, Cambridge, pp. 389-401

Vílchez C, Forján E, Cuaresma M, Bédmar F, Garbayo I, Vega JM (2011) Marine carotenoids: biological functions and commercial applications. Mar Drugs 9:319-333

Xia S, Wang K, Wan L, Li A, Hu Q, Zhang C (2013) Production, characterization, and antioxidant activity of fucoxanthin from the marine diatom Odontella aurita. Mar Drugs 11:2667-2681

Yamamoto HY, Nakayama TO, Chichester CO (1962) Studies on the light and dark interconversions of leaf xanthophylls. Arch Biochem Biophys 97:168-173 